\title{
Socioeconomic Characteristics and the Impacts of Land Use Changes to Sugar Cane in Quirinópolis, Brazil
}

\author{
Jean Marc Nacife ${ }^{1}$, Frederico A. Loureiro Soares ${ }^{1} \&$ Gustavo Castoldi $^{1}$ \\ ${ }^{1}$ Postgraduate Program in Agricultural Sciences, Federal Institute Goiano (IFGoiano), Rio Verde, Brazil \\ Correspondence: Jean Marc Nacife, Postgraduate Program in Agricultural Sciences, Federal Institute Goiano, \\ Rio Verde, Brazil. Tel: 55-649-9963-4589. E-mail: jean.nacife@ifgoiano.edu.br
}

Received: April 13, 2019

Accepted: May 16, 2019 Online Published: July 15, 2019

doi:10.5539/jas.v11n10p180

URL: https://doi.org/10.5539/jas.v11n10p180

\begin{abstract}
The socioeconomic impacts arising from the change in the traditional productive systems for sugar cane have caused weightings. This article proposes to investigate the socioeconomic characteristics and impacts of the use of the land with cane field, by using municipal indicators and agricultural establishments of Quirinópolis. The field survey used margin of sampling error of 5\% and a confidence level of $95 \%$, sampling 58 establishments and aiming to analyze their characteristics and impacts in function of this change by means of socioeconomic indices proposed, statistical tests and correlations. We used the survey methodology applying inferential statistical techniques, cluster analysis, Spearman correlation tests of normality (Kolmogorov-Smirnov and Shapiro-Wilk) and hypothesis tests (Wilcoxon Test). The analysis of the socioeconomic indices approached two perspectives. In the Municipal Prospect, found that the indexes: IFDM-2005 [0.6713], IFDM-2016 [0.8387] and IFDM-V [0.1996]. The indices show the range of a high municipal development. In the analysis of agricultural establishments, the indices assessed the following values: rural exodus [-0.09], succession [1.44], association [3.75], rural heritage [-0.44 and -0.04] and overall remuneration [0.57]. About land use change, it was detected that occurred mostly in pastures converted to sugar cane; there is a correlation between the indices that the Wilcoxon tests confirmed the statistical significance at the level of 5\% (p-value). It is concluded that the socioeconomic impacts promoted from change in land use of traditional productive systems for sugar cane were overwhelmingly positive and promoted the development in a view of municipal and agricultural establishments in the period studied.
\end{abstract}

Keywords: agricultural economics in Goiás, sugarcane agroindustry, system of production of sugarcane

\section{Introduction}

Brazil is recognized as a world leader in agricultural production, even with the producer of agribusiness coexisting with high taxes rates, high logistics costs, bureaucracy, among other limiting factors. The growth in agricultural production has been high in recent years, the data shows that the agribusiness sector has remained as a pillar of Gross Domestic Product (GDP) of Brazil, according to research by the Center for Advanced Studies in Applied Economics (CEPEA), Esalq/USP, in partnership with the National Confederation of Agriculture (CNA) the participation of agribusiness contributed $23.5 \%$ to the GDP national in 2017, being responsible for approximately $37 \%$ of jobs and $41 \%$ of our exports in 2016 , thus help to prevent the advance of inflation in 2017 (CEPEA, 2018A).

The culture of sugar cane appears in this scenario of strength of the business sector of agriculture with very strong growth in recent years because of the need for renewable fuels and promoting impulse to economy. In addition, this sector increasing was consolidated by the growing interest in alternative energy sources and renewable fuels with less impact to the environment (Gilio \& Moraes, 2016). In the center-west region, the state of Goiás has received in recent years, the larger investments of the sugar-alcoholitics sector and increased their participation very significantly in national and international markets, inducing a strong impact on the economy, land use and social issues that have sued recent studies, once that, consequently, agricultural production has been moved to other regions and even restricted in function of this phenomenon (Trindade, 2015; Petrini et al., 2017). Specifically, the state of Goiás jumped to 200,048 tons in 2005 to $69,726,355$ tons of sugar cane in 2016, being ranked as the second largest national producer, only lagging of São Paulo, with $354,353,922$ tons, according to the census of agriculture in 2017 (IBGE, 2018a). 
The research undertaken focused in an original way directly with the agricultural producer establishments of sugar cane, with geographically restricted locus to Quirinópolis region, located in Goiás southwestern. Quirinópolis was chosen for its uniqueness and specificity, staying in first place in the ranking of municipalities producers of sugar cane in Goiás and secondly in this question, considering the whole of Brazil, with the production of 7,142,253.25 tons of sugar cane, in accordance with the Census of Agriculture 2017 (IBGE, 2018a). In this perspective, the agricultural establishments of Quirinópolis are important for the agricultural economy of Goiás and the country, where studies on the change of the productive system (cattle, crops of corn, soybean and sorghum for sugar cane) in rural establishments contribute to the evaluation of the socioeconomic indicators and for regional development (Dzanja, 2018).

Recent studies have analyzed the impacts of the expansion of sugarcane planting for the Agribusiness of biofuels, increasing the perception of problems mainly for environmental and social order, as in the management and occupation of the land, with the workers, small landowners and the local community (Petrini et al., 2016, 2017; Trindade, 2015; Gilio \& Moraes, 2016). Within the context of the dimensions of research, the article focuses on the central problem in social and economic spheres from the perception of the owners of the agricultural establishments, as well as the socioeconomic development due to the municipality, differentiating itself, thus, further studies on the insertion of the cultivation of sugar cane. This article contributes with other studies (Assunção et al., 2016; Garrett et al., 2013), since also goes on topics relating to productive economies of scale offered by agribusiness, factor that provides the reduction of production cost, and may induce individuals to sell, rent or convert pastures or soy in sugar cane, modifying the land use.

A new vision that has been placed in debate with the advent of the expansion of the productive cultivation of sugar cane involves the fact of its competition with the agricultural production of food and its negative impacts on the exchange of land use (Maroun \& Rovere, 2014; Dauvergne \& Neville, 2010). The current study enables to identify, regarding the use of land, crops replaced with the change promoted with this expansion in a consolidated region with high index of production in agriculture (IBGE, 2018a). Regarding the socioeconomic issues, Oliveira et al. (2014b) presents the research results, which demonstrates improvements in average socioeconomic indicators in producing regions of sugar cane. It was also found that the migratory flow to the work related to the sugar cane has been absorbed through the creation of formal jobs expressed by the variable employment and income of the FIRJAN Index of Municipal Development (IFDM). The proposal of this study is important not only because it presents a series of indices that allow analysis, but also makes it possible to identify the strengths and weaknesses and compare with counterparts, as stipulates Simms et al. (2014), with the use of indicators from a tool of benchmarking proposal to rural communities in Newfoundland and Labrador, Canada.

Many studies have been published seeking to understand the impacts of economic, social, environmental (Santos et al., 2017; Trindade, 2015; Oliveira et al., 2014b; Medina et al., 2015) and, above all, pointing out the mechanisms for the sustainability of the sugar cane industry (Gilio \& Moraes, 2016; Spera et al., 2017). Clearly, the vast majority of the studies are directed to issues of economic and environmental sustainability, but the social issues still need to be further studied. There are several scientific studies that suggest benefits for the population of the regions of expansion of the sugar cane industry in Brazil, citing, mainly, the generation of employment and income (Mangoyana et al., 2013; Ribeiro, 2013). In Brazil, the governments at the federal and state have proposed regulations with the regulatory function, in the perspective of reducing the social and environmental impacts that the deployment of the cultivation of sugar cane and the agro-industry can promote, even proposing zoning laws, environmental regulations and promoting agreements in area of labor rights (Duarte et al., 2013).

In this context, a plausible hypothesis relates that the socioeconomic impacts relating to the characteristics of the change in the productive system for sugar cane indicate that the relationship between remuneration $\mathrm{X}$ costs; immigration X emigration and technical preparation of the owners in the context of agricultural establishments were positive and in growth occurred in the municipal development Index FIRJAN, in the period studied. The study included empirical producers' considerations and assumes that the exodus rate directly impacts on the quality of conservation of divisions and cattle pen in these properties. Through the above, it is possible to use the data and information from the article for benchmarking and not only be used as a list of indices, providing rural leaders a "scoreboard information" that contributes in the process of preparing strategies for the development (Simms et al., 2014), since the objective of this study is to explore the relationship between the characteristics of the owners, agricultural establishments with the indicators of the social dimension and the economic dimension, noting the main impacts of land use change on the basis of the indices proposed by the municipality of Quirinópolis, the largest producer of sugar cane of Goiás and second largest producer of Brazil (IBGE, 2018a). 


\section{Method}

In this section, we present the parameters used para create a dashboard Key Performance Indicator (KPI) to evaluate the growth of development in the context of municipal indicators and an empirical model for analysis of the development of agricultural establishments producers of sugar cane in Quirinópolis, Goiás State, Brazil. In the perspective of the municipality, the Municipal Development Index FIRJAN (IFDM) indicator, which values the level of socioeconomic development of a municipality, which enabled us to verify the impact of the expansion of the productive system of sugar cane from the variables contained in the dimensions of education, health, employment and income. Already inside of the perspective of local agricultural establishments, it was necessary to develop a list of indices aiming to probe the impacts on land use and the agriculturist that changed its production system in rural property.

The field research was carried out in the period from June 2018 to February 2019, with the owners based on the characteristics of its agricultural establishments that are located in the rural 21 microregions of the municipality of Quirinópolis. The municipality is geographically located in the coordinates: $18^{\circ} 26^{\prime} 52^{\prime \prime}$ south latitude and $50^{\circ} 27^{\prime} 07^{\prime \prime}$ west longitude, its average altitude of 541 meters, located in southwest Goiás, in the mesoregion South Goianian in which covers 15 municipalities are directly linked to the hydrographic basin of the Paranaíba River (IBGE, 2018b).

For sample size calculation, we considered the 67 agricultural establishments producers of sugar cane (IBGE, 2018a), constituting the universe of the research. These agricultural establishments produced 7,142,253.25 tons of sugar cane in 86,262.056 hectares, according to Census of Agriculture 2017 (IBGE, 2018b). The search for the calculation of the sample was $95 \%$ degree of reliability of the data presented and analyzed. Of this total, we worked with a margin of sampling error of $5 \%$, investigating a sample with 58 responses from the owners of agricultural establishments for interviews (Santos, 2016).

\subsection{Measures and Covariates}

In order to comply with the objectives in relation to agricultural establishments, has undertaken a survey of quantitative type, with the support of inferential statistics (Cooper \& Schindler, 2016), applying in the field research the survey method (Creswell, 2017). In the collection of data, structured questionnaires were used printed for the interviews. The focus of the questionnaires was to gather information on the impact promoted by the change of production system and cultures, contemplating the variables listed in Table 2). The questionnaire for data collection was divided into two distinct sections. The first section collecting general data about the profiles of the owners and agricultural establishments, and the second the conceptions about the variables of research framed in the social and economic dimensions of the productive system of sugar cane.

In the first phase of the research, was applied to the pre-test of the questionnaire in the field to check the rate of inconsistency between the questions raised, being possible to correct the ambiguity and errors of questions. Subsequently, they were added to the questionnaire changes and improvements needed in the light of the pre-test. In the next moment, considering the size of the sample with 58 questionnaires, ran to the field activity by applying the instrument to the interviewees. It spanned 21 microregions (Sete Lagoas, Paredão, Cachoeira do São Francisco, Córrego Raso/Fundo, Mandengo, Fortaleza, Confusão, Limeira, Bruacas, Salgado, Cachoeirinha, Perdizes, Douradinho, Guariroba, Pedra Lisa, Viradouro, Lenda, Inhumas, Alegre, Rosa, Invejosa) and the headquarters of county from Quirinópolis to obtain the quantity that meets the specified sample.

The research on its universe covers agricultural establishments, as defined by IBGE (2018a), with contractual relationship for lease and supply of sugar cane linked to sugar-alcoholitics agroindustries exclusively located in the municipality of Quirinópolis, Goiás State, Brazil.

\subsection{Research Design}

The process of collecting and processing the data of field research was developed in stages: (I) preparation of the questionnaires and codification of the questions to facilitate access to and linking responses to groups of agricultural establishments studied; (II) tabulation of data; (III) a preliminary analysis of the data, assessment of the adequacy of the sample and descriptive measures; (IV) evaluation of the method of extraction of factors and the decision modeling for the tests and correlations relevant; and $(\mathrm{V})$ exploitation of the data by means of statistical analysis (Cooper \& Schindler 2016; Creswell, 2017). IBM SPSS Statistics 24.0.0.0® and Microsoft

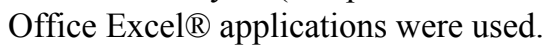

Seeking to determine whether there was a rural exodus in function of the change in the productive system, it was applied the $t$ test to determine if the average index of Exodus is equal or greater than zero (given the statistical significance, $P<0.05$ ). When it is verified that the average is greater than zero, then there was a rural exodus; 
otherwise, there were not. It is also adjusted the test of correlation for the Index of Exodus and the indices of rural property, in order to determine the correlations. Performed statistical tests still of normality and hypotheses, as well as the analysis of clusters.

\subsection{Instrumentation and Statistical Analysis}

The research carried out in this study developed and articulated the indices in the municipal scope with the model of the indicator that incorporates all aspects of socioeconomic development adapted from Pereira and Moreira (2016), allowing an analysis of the database of governmental officials of Brazil with the recognized methodology of the IFDM.

For better understanding, it is noteworthy that the IFDM, in any dimension evaluated, assigns score that ranges from 0 to 1, allowing you to classify the municipalities for purposes of comparison and benchmarking (Simms et al., 2014), by means of reference values, thus the FIRJAN conventionally four categories of development for the IFDM of municipalities, in which: IFDM between 0.0 and $0.4=$ Low stage of development, IFDM between 0.4 and $0.6=$ regular development, IFDM between 0.6 and $0.8=$ moderate development, and IFDM between 0.8 and $1.0=$ high stage of development. The results are composed of variables in three dimensions of development: IFDM-Employment \& Income (IFDM myself), IFDM-Education (IFDM) and IFDM-Health (IFDM-H), as well as the consolidated index (IFDM), calculated by the arithmetic average of the three indexes segmented (FIRJAN, 2018). The dimensions and variables of the IFDM, by FIRJAN (2018):

IFDM-Employment \& Income-Pillars: formal labor market; Indicators used: generation of formal employment; absorption of local formal labor; income generation; Avg average formal employment wages; and inequality. Source: Ministry of Labor and Social Welfare (MTPS).

IFDM-Education-Essential Pillars: education, infant education and quality of education. Indicators used include enrollment in early infant education; abandonment in deep teaching mental health; age-grade distortion in elementary school; average daily classroom hours in elementary school; result of Basic Education Development Index (Ideb) in elementary education. Source: Ministry of Education (MEC).

IFDM-Health-Pillars: primary care, first level society's contact with thehealth system. Indicators used: number of prenatal consultations; deaths from ill-defined causes; child deaths due to avoidable causes; and attention-sensitive hospitalização basic. Source: Ministry of Health (MOH).

The authors, for the analysis from the perspective of the socioeconomic development of the municipality of Quirinópolis, used the definitions and mathematical models contained in the methodology of calculation of the FIRJAN (2018), and to assess the impacts of change of the system of production of traditional culture and livestock for sugar cane, propose the measurement of the variation of the ifdm in time as an indicator. Thus, we used the ifdm of year of implementation of change (year 2005) and compared them to the IFDM the last year of the calculation of the indices that was in 2016, obtaining the proportion of the variation of the index. Following the equation used for the mathematical calculation:

$$
\mathrm{IFDM}_{\mathrm{V}}=1-\frac{\mathrm{IFDM}_{2005}}{\mathrm{IFDM}_{2016}}
$$

where, 1 = constant of the equation; IFDM $_{\mathrm{V}}=$ Variation of IFDM; IFDM $_{2005}=$ IFDM-Consolidated Index for the year 2005; $\mathrm{IFDM}_{2016}=$ IFDM-Consolidated Index for the year 2016;

The socioeconomic indicators applied to agricultural establishments in function of the phenomenon of change in the productive system for sugar cane were offered from a methodological construction in which were grouped into variables and indicators, in which fall into dimensions, setting an empirical model in the following way:

Social Dimension-Pillars: Exodus, succession and association. Indicators used: residents before and after residents, successors and conflict resolution, representation and negotiation. Source: field research.

Economic Dimension-Pillars: rural heritage, revenue and attractiveness of the business. Indicators used include fences and corrals, remuneration and liquidity, guarantee of income, profitability, production system, state of health, need for investment and exploitation of the earth. Source: field research.

For convergence of statistical treatments used and implementation of empirical model of analysis of the socioeconomic impacts, is presented in Table 1, the equations and definitions of the indices proposed to characterize the change in the productive system in agricultural establishments in kelston. 
Table 1. Rural indicators for the socioeconomic evaluation of the sugarcane production system

\begin{tabular}{|c|c|c|}
\hline Index & Equations & Description \\
\hline Exodus (IEcane) & $\mathrm{IE}_{\text {cane }}=\frac{\mathrm{R}_{\text {previous }}-\mathrm{R}_{\text {after }}}{\mathrm{R}_{\text {previous }}}$ & $\begin{array}{l}\text { Measures the number of people who have emigrated from } \\
\text { agricultural property after the change of the productive system, } \\
\text { checking the rural exodus site (linear Scale Rating: }[-], \text {, } 0 \text { " [+]). }\end{array}$ \\
\hline Association (IA) & $\bar{X}=\frac{\sum_{i=1}^{N} \overline{X_{i}}}{N}$ & $\begin{array}{l}\text { Measured by the arithmetic average of the values obtained for the } \\
\text { variables: representativeness, conflict resolution and negotiation, } \\
\text { the perception of the benefits generated by a representative body } \\
\text { (Likert scale by assigning Notes: } 1 \text { to } 5 \text { ). }\end{array}$ \\
\hline Succession (IS) & $\mathrm{IS}=\frac{\mathrm{SAE}}{\mathrm{AEO}}$ & $\begin{array}{l}\text { Measures the condition of continuity in the management of rural } \\
\text { business from members of the families of the owners of the } \\
\text { agricultural establishments. Evaluates if the indicator by means of } \\
\text { linear, positive values if there are successors to the agricultural } \\
\text { establishments. }\end{array}$ \\
\hline $\begin{array}{l}\text { Global Remuneration (IGR): } \\
>\quad \text { Remuneration Scenario } \mathrm{X}_{1} ; \\
>\quad \text { Remuneration Scenario } \mathrm{X}_{2} ; \\
>\quad \text { Remuneration Scenario } \mathrm{X}_{3} .\end{array}$ & $\begin{array}{l}\bar{X}=\frac{\sum_{\mathrm{i}=1}^{\mathrm{N}} \overline{\mathrm{X}_{\mathrm{i}}}}{\mathrm{N}} \\
\mathrm{X}_{1}=1-\frac{\mathrm{R}_{\text {Selic }}}{\text { Cane }_{\mathrm{R}}} \\
\mathrm{X}_{2}=1-\frac{\mathrm{R}_{\text {Prod }}}{\text { Cane }_{\mathrm{R}}} \\
\mathrm{X}_{3}=1-\frac{\mathrm{R}_{\mathrm{US} S}}{\text { Cane } \mathrm{R} S}\end{array}$ & $\begin{array}{l}\text { Measured by the arithmetic average variation of the income of } \\
\text { agricultural property with the change in the productive system for } \\
\text { sugar cane. Is the ratio between the revenues in the year of the last } \\
\text { harvest of traditional culture by revenue established in } 2018 \text { with } \\
\text { the sugarcane. The index of total revenue is composed by three } \\
\text { scenarios proposed to fix: Selic Rate }\left(\mathrm{X}_{1}\right) \text {, quote the product }\left(\mathrm{X}_{2}\right) \text { in } \\
\text { the Harvest and quote the harvest in dollar }\left(\mathrm{X}_{3}\right) \text {-(linear scale of } \\
\text { assessment: }[-] \text {, " } 0 \text { " [+]). For correction with the Selic rate, the } \\
\text { scenario } \mathrm{X}_{1} \text {, we used the following formula: } \\
\left\{\left[\left(\frac{\sum_{\mathrm{j}=1}^{\mathrm{n}} \mathrm{L}_{\mathrm{j}} \mathrm{v}_{\mathrm{j}} \mathrm{v}^{2}}{\sum_{\mathrm{j}=1}^{\mathrm{n}} \mathrm{v}_{\mathrm{j}}}\right)^{252}-1\right] \times 100\right\} \% \text { ao ano } \\
\text { Adopted the BCB methodology (2019). Since the scenarios } \mathrm{X}_{2} \text { and } \\
\mathrm{X}_{3} \text { used the quotations extracted from the CEPEA (2018B). All } \\
\text { scenarios had the calculations of the remuneration of the sugar cane } \\
\text { by CONSECANA (2018) of } 10 \text { July } 2018 \text { and the conversion into } \\
\text { dollars on that date by the quotation of Banco Central do Brasil } \\
\text { (BCB, 2019). }\end{array}$ \\
\hline $\begin{array}{l}\text { Rural Patrimony (IRP): } \\
>\quad \text { Cattle Pen (y); } \\
>\quad \text { Division }(\mathrm{x})\end{array}$ & $\overline{\mathrm{Y}}=\frac{\sum \mathrm{y}_{\mathrm{if}_{\mathrm{i}}}}{\sum \mathrm{f}_{\mathrm{i}}} ; \overline{\mathrm{X}}=\frac{\sum \mathrm{x}_{\mathrm{if}_{\mathrm{i}}}}{\sum \mathrm{f}_{\mathrm{i}}}$ & $\begin{array}{l}\text { The index measured by the weighted average of the extension (with } \\
\text { weight 2) and conservation (1) weight of the fence and Corral, if } \\
\text { there was an increase or reduction of these physical rural heritage, } \\
\text { comparing the before with the later from the change in the system } \\
\text { (linear Scale) }\end{array}$ \\
\hline
\end{tabular}

Source: Application of the equations adapted from the FIRJAN methodology (FIRJAN, 2018).

In addition to the indices, it took tests statistics to support the analyses of data, such as the method of minimum variation of Ward for formation of clusters, using the following equation:

$$
\Delta \mathrm{E}=\frac{\mathrm{m}_{\mathrm{p}} \cdot \mathrm{m}_{\mathrm{q}}}{\mathrm{m}_{\mathrm{p}}+\mathrm{m}_{\mathrm{q}}} \cdot \sum_{\mathrm{i}=1}^{\mathrm{i}=\mathrm{n}}\left(\mathrm{x}_{\mathrm{ip}}-\overline{\mathrm{x}}_{\mathrm{iq}}\right)^{2}
$$

The Spearman correlation test (non-parametric method) that uses only the jobs, and does not make any assumptions was used to verify the hypotheses, the correlation coefficient using the formula:

$$
\mathrm{N}_{\mathrm{r}} \geq 10, \mathrm{z}=\frac{\mathrm{W}}{\sigma_{\mathrm{W}}}, \sigma_{\mathrm{W}}=\sqrt{\frac{\mathrm{N}_{\mathrm{r}}\left(\mathrm{N}_{\mathrm{r}}+1\right)\left(2 \mathrm{~N}_{\mathrm{r}}+1\right)}{6}}
$$

The value $r$ is always between $r>0$ and $r<0$, with $r=0$ corresponding to the non-association. The correlation is positive, and in this case as $X$ increases, it also increases $Y$, and the negative correlation is when, and in this case as $X$ increases, $Y$ decreases. The higher the value $r$ (positive or negative), the stronger the association (Myers et al., 2013).

Another test applied was the non-parametric Wilcoxon test, in which uses the jobs of sample data consisting of matched pairs. It is used to test for differences in population distributions, where the null and alternative hypotheses are:

$H_{0}$ : from populations with the same distribution. $H_{l}$ : from populations with different distributions. 


\section{Results and Discussion}

\subsection{Indexes at the Municipal Level}

Based on the data collected, tabulated and processed, verified the results for the IFDM, as described in Figure 1 and having as a basis for calculating the years 2005 and 2016. The analysis identified the Quirinópolis in class of moderate development in 2005 and that rose, reaching, in 2016, the track of development. In the comparison of periods, the IFDM-Health Development was moderate (0.6851) to high (0.9043)-variation of 0,320; Education began to develop moderate $(0.6713)$ to high $(0.9180)$-variation of 0,367 ; and IFDM-Employment \& Income went to the value of 0.6851 to 0.6936 , expressing a variation of 0,055 . This growth in all dimensions impacted on IFDM consolidated, promoting the development of greater range.

The observation of the results under the dimensional approach of economic indicators of the FIRJAN Index infers that the development was lower in comparison to the social indicator of the periods analyzed, may have cause attributed to global financial economic crisis (Gilio \& Moraes, 2016), affecting the country and also the agribusiness of sugar cane mainly in the years 2015, 2016 and 2017, even with the reduction in the total area planted (IPEA, 2018; IBGE, 2018b), influencing, consequently, Goiás and also Quirinópolis.

It should be emphasized that the indexes show, above all, an increase of over $5 \%$ in employment and income variables, even with a deep crisis. The results indicate that the social indexes consider a consolidation of achievements less perennials, composed variables related to education and health, allows us to infer that the social gains are less vulnerable in the short term than the rentals in what refers to the municipal scope in terms of development and these indexes were responsible for the great increase of high development of Quirinópolis.

Assessing the IFDM-V now proposed, get yourself (within a linear scale, whether positive or negative, where " 0 " is the inflection point of the variation of growth) the indicative of growth of development has the value of 0.1996, indicating a positive variation consolidated socioeconomic municipality, after changing the use of land for sugar cane from the various local agricultural establishments to meet the sugar-alcoholitics agribusiness in the municipality. For a better understanding of the expression that result from the municipality of Quirinópolis, was applied to the proposed methodology of the IFDM-V for the four municipalities with higher GDP of the state of Goiás (IBGE, 2019), for purposes of reference: Goiânia (IFDM-2005 $=0.7246 /$ IFDM-2016 $=0.8170$ ), had IFDM-V equal to 0.1131; Anápolis (IFDM-2005 $=0.7185 / \mathrm{IFDM}-2016=0.8014$ ) had IFDM-V equal to 0.1034; Aparecida de Goiânia (IFDM-2005 $=0.6936 /$ IFDM-2016 $=0.7709$ ) had IFDM-V equal to 0.1003; and Rio Verde $($ IFDM-2005 $=0.7848 /$ IFDM-2016 $=0.8029)$ had IFDM-V equal to 0.0225 . Another valid reference is that Quirinópolis, in 2005, occupies the 39th state place by IFDM and, in 2016, went to occupy the 4th place among the municipalities of Goiás (FIRJAN, 2018).
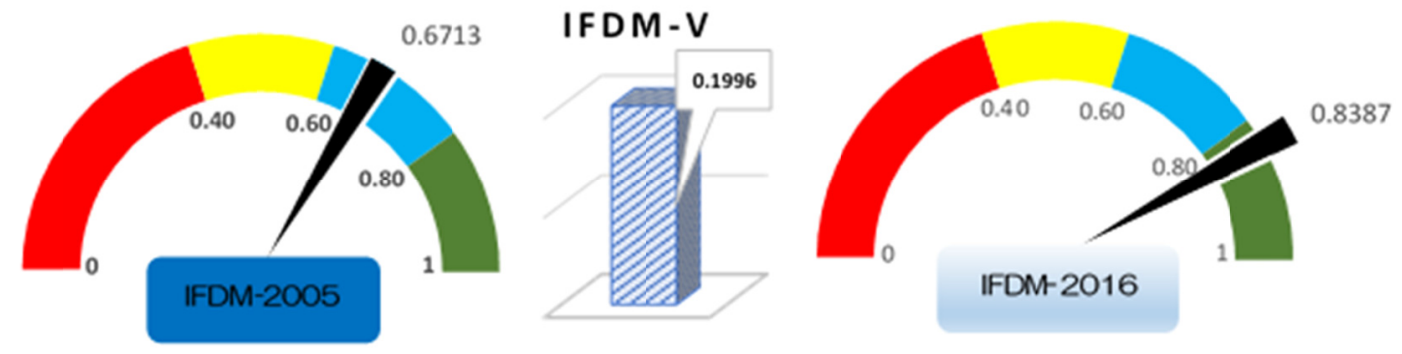

Figure 1. KPI Development of Quirinópolis: IFDM-2005, IFDM-2016 and IFDM-V

Note. calculation of the IFDM-V based on indexes FIRJAN (2018).

Oliveira et al. (2014a), in his research, infers that there were improvements in average socioeconomic indicators in producing regions of sugar cane. Their studies also indicate that the migratory flow to the work comes from sugar cane has been allocated to the creation of formal jobs, positively impacting on employment and income dimension of the FIRJAN Index of Municipal Development (IFDM-EI). Based on the data, calculations and studies cited, it is inferred that Quirinópolis had important performance between the municipalities of the state in the indices IFDM and IFDM-V (proposed by the authors), and in the municipal scope, the socioeconomic impacts based on the contents of the IFDM were extremely positive, indicating high development, confirming the studies comprising that focus on the improvement of the socioeconomic indicators from the conversion of the 
use of land for sugarcane cultivation (Oliveira et al., 2014b; Gilio \& Moraes, 2016; IPEA, 2016; Pereira \& Moreira, 2016).

\subsection{Indexes at the Agricultural Establishments Level}

\subsubsection{Profile-Level Indexes of Owners of Agricultural Establishments}

In order to enable a better understanding of the results of the field survey, it was found that the first profile of owners and agricultural establishments studied, which will be contrasted with the result of the agricultural census of 2017, 1.234 establishments of the rural sector in general for the purposes of analysis (IBGE, 2018a). General data of the Livestock owners in the municipality of Quirinópolis show that $86.70 \%$ were male and $13.30 \%$ female (IBGE, 2018a). In the field data there were $87.93 \% 12.07 \%$ male and female. There is a similar proportionality between the numbers of the sugar cane producer sector with the general, demonstrating a similarity of demographic data.

The general data concerning the age of the owners of agricultural establishments indicate that $51.63 \%$ have more than 60 years; $46.90 \%$ are between 30 to 60 years; and only $1.47 \%$ has less than 30 years of age (IBGE, 2018a). Extracted from the field research the minimum age of 27 years, the maximum of 85 years and an average of 55 years for sugarcane producers.

In relation to the general level of education of individuals of the municipality, according to the IBGE (2018a), $24.43 \%$ have equivalent to incomplete basic education, $29.87 \% 27.60 \%$ elementary, middle school, $13.04 \%$ to higher education, $4.81 \%$ without formal schooling; and only $0.25 \%$ with post-graduation. In contrast, measured that owners of agricultural establishments of sugar cane producers have a grade level higher than the general average of individuals of the municipality, in which $6.90 \%$ have equivalent to incomplete basic education, $13.79 \% 34.08 \%$ elementary, middle school, $27.59 \%$ higher education, $34.10 \%$ do not have formal schooling; and only $6.90 \%$ have postgraduate programs.

Also referring to the agricultural census of 2017, it is possible to check the frequency of participation of Quirinópolis producers in events of technical information, in which $73.40 \%$ reported that seek some form and $26.60 \%$ never participate (IBGE, 2018a). To compare with the data from field research, we realize that the producers of sugar cane culture have a much lower rate of disinformation with only $10.34 \%$ of the respondents, indicating that they are more concerned with the technology applied to your production system than the general profile of the municipality. Figure 2 demonstrates the formation of the ideal point of clusters in this work, making it possible to perceive the distance between the possible clusters and the point of approximation of the optimal clusters that the graph displays for analysis. Since this graph shows the incidence of grouping adopted and those that were not selected, it is possible to perceive the differences that the technique applies for agglomeration of the variables.

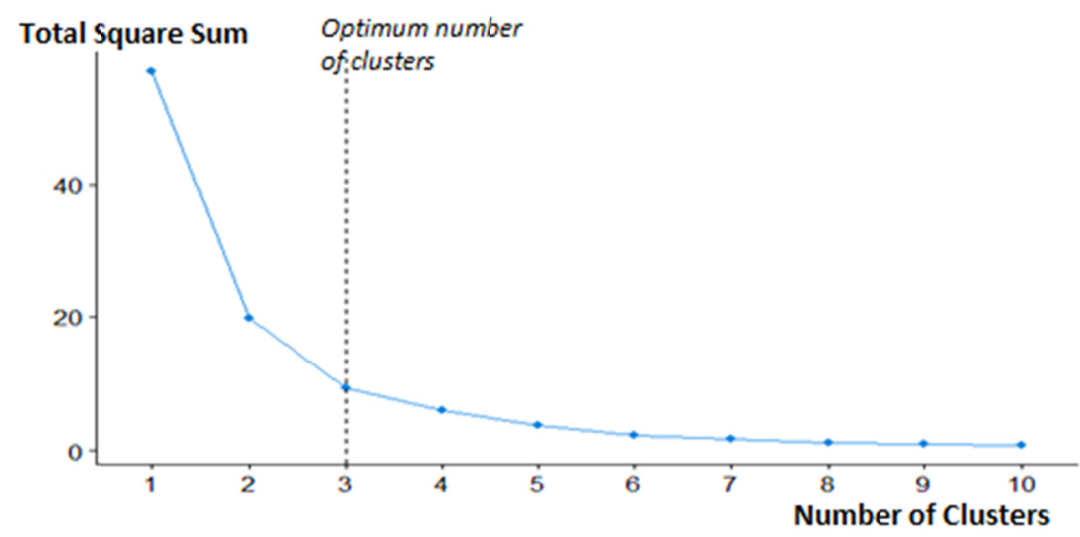

Figure 2. Graph of cluster analysis is owner profile

The graph of Figure 3 presents us with the optimal number of clusters to be formed from the ages of the owners, and so that you can check, form 3 clusters. The following is the dendrogram with the groups formed, so that the owners that belong to the same group have ages next to each other. To obtain the track dendrogram groups, we used the method of Ward. 


\section{Cluster Dendrogram}

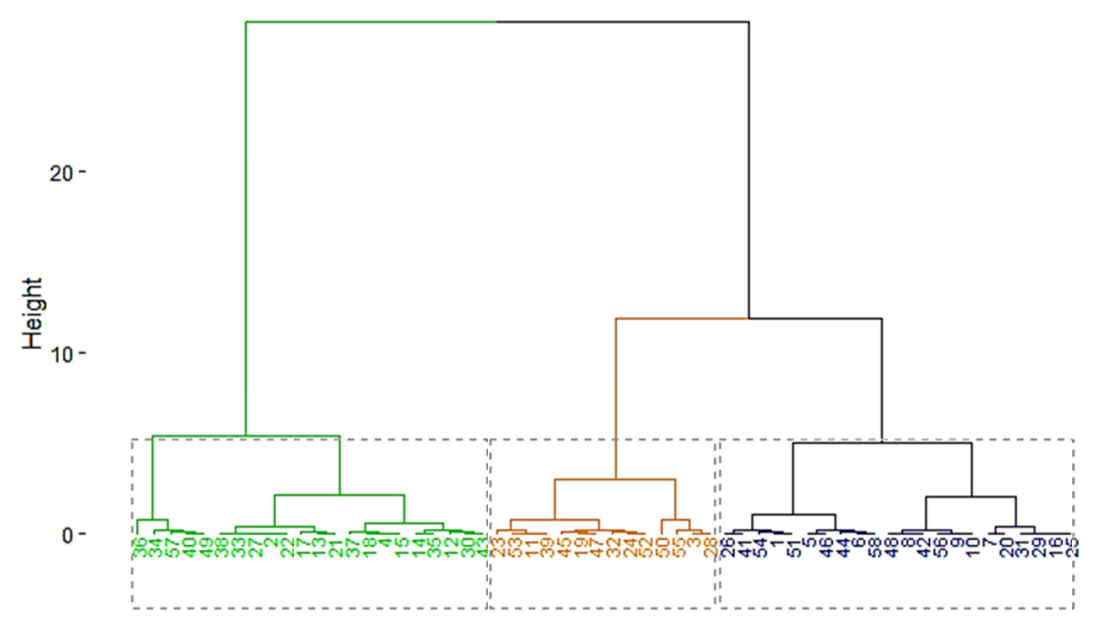

Figure 3. Dendrogram of clusters

Then, it presents a table with the number of owners allocated in each cluster and the average age of the owners. Based on the results obtained for the mean age of the owners for each cluster, we found that the cluster 3 is the lowest quantitatively and presents a higher average compared to others who have the same quantity. It emerges with the data that the owners are in a mostly mature adult age, and from additional calculation, the average age is 55 years.

Table 2. Cluster is owner profile

\begin{tabular}{lll}
\hline Clusters & Amount & Average (Age) \\
\hline $\mathbf{1}$ & 22 & 58.00 \\
$\mathbf{2}$ & 22 & 42.18 \\
$\mathbf{3}$ & 14 & 72.43 \\
\hline
\end{tabular}

It can be inferred that the profile of the sugar cane producer of Quirinópolis is formed mainly by men, on average with 55 years of age, who possess the teaching medium and are updated in their great majority with technical information about your production system that has opted. It is the innovative character of the research, since they are data extracted from primary source and compared with the official statistics of the sector. It should be noted that, as goals described for this study, the profile is important for the characterization of the target public.

\subsubsection{Indexes in Agricultural Establishments}

Studies of the system of production of sugar cane have displayed lack of consistent evidence about the social impacts (Ribeiro, 2013). Brazil has been impacted with strong rural exodus in recent decades (Maia et al., 2016). In this way, the result of this research is relevant in function of the index of exodus be negative in relation to agricultural establishments of the productive system of sugar cane in Quirinópolis, indicating that the productive system produced a greater presence in the field unlike the general panorama of Brazil, as shown in Table 6.

Table 3. Exodus, succession, and association indexes (Social Dimension)

\begin{tabular}{|c|c|c|c|c|c|c|c|c|}
\hline \multicolumn{3}{|c|}{ Index Exodus } & \multicolumn{2}{|c|}{ Index Succession } & \multicolumn{4}{|c|}{ Index Association } \\
\hline Previous Residents & Currents Residents & $\mathbf{I E}_{\text {cana }}$ & Successors & IS & Conflict Resolution & Representative-ness & Negotiation & IA \\
\hline 233 & 253 & -0.09 & 82 & 1.44 & 3.57 & 4.34 & 3.34 & 3.75 \\
\hline
\end{tabular}

The field activities indicated a condition of successors in $44 \%$ greater than the number of owners specifically in agricultural establishments of this study, a lower number in comparison with the overall indicative of establishments of the municipality who obtained a score of $85 \%$ (IBGE, 2018a). The IS obtained is positive in 
the sense of family business succession and suggests a margin of possible quantitative analysis of possible successors to the rural enterprises of the system of production of sugar cane.

The index of association was recognized with degree of significance of $75 \%$ approval, considering scale from 0 to $100 \%$ of relevance for the producers of sugar cane, in which glimpses the variable represented the most important, followed by conflict resolution and negotiation, confirming the findings of similar studies that have identified that the organization is an influential factor in socioeconomic compound for individuals (Spera et al., 2017), referring to the strong lobbies of representative bodies (Guanziroli et al., 2013).

The individuals who convert their land for sugar cane hardly return the pastures or traditional crops cultivated previously due to the high cost of conversion and often yields higher levels of sugar cane production (Egeskog et al., 2016). Empirical survey conducted in the initial workshop of the survey found, along the leadership of rural producers from Quirinópolis, a concern on the reduction of the rural heritage (fences and corrals) in agricultural establishments after implantation of the productive system of cane. This concern finds warranties in researches in which covers the cost of the conversion of land use after the implementation of the sugar cane culture (Spera et al., 2017; Guanziroli et al., 2013; Egeskog et al., 2016; Petrini et al., 2017).

The data bring that in fact there was a significant reduction in the extent of the fences of rural properties, which can be explained by the specificity of mechanized farming of sugar cane that has been deployed, which demand large areas for planting, harvesting and treatment of culture. The conservation status have worsened is one more point that ratifies the conversion cost as an obstacle to productive system relocation.

Table 4. Rural patrimony indexes (Economic Dimension)

\begin{tabular}{llllll}
\hline \multirow{2}{*}{ IRPx } & \multicolumn{2}{c}{ Index Division } & & \multicolumn{2}{c}{ Index Cattle pen } \\
\cline { 2 - 3 } \cline { 5 - 6 } & Extension & Status & & Size & Status \\
\hline $\mathbf{- 0 . 3 7}$ & -0.44 & -0.24 & $\mathbf{0 . 0 4}$ & -0.02 & -0.08 \\
\hline
\end{tabular}

bouts the index of corral which follows the same logic of the index, both proposed by the authors, there has been a worsening condition, although not significant (below 5\%), indicating that the structure of the corral is being maintained even with the operation of other productive system different from livestock.

Table 5. Global remuneration index (Economic Dimension)

\begin{tabular}{llll}
\hline Scenario 1 & Scenario 2 & Scenario 3 & $\overline{\mathbf{X}}$ \\
\hline Rate Selic & Product Quotation (RS \$) & Product Quotation (US \$) & \multirow{2}{*}{ IGR } \\
\hline $\mathbf{X}_{\mathbf{1}}$ & $\mathbf{X}_{\mathbf{2}}$ & $\mathbf{X}_{\mathbf{3}}$ & \\
\hline $\mathbf{0 . 4 3}$ & 0.62 & 0.65 & $\mathbf{0 . 5 7}$ \\
\hline
\end{tabular}

The empirical data collected along the agricultural establishments follow the current studies on economic viability in agriculture, investigating and apportioning per hectare (ha), income/ha and the cost/ha (Strelecek et al., 2011; Oliveira et al., 2014b; Barnes et al., 2015). Thus, the verification of the average revenue/ha generated in different production systems involved enabled the creation of scenarios already exposed in the methodology of this research. In relation to the results realized in the three scenarios, it is important to highlight that, the first, is that the composite index for the comparison between the total revenue obtained with the productive system prior to the sugar cane by income from this and corrected along the time by the Selic rate. The IGR found the average number of scenarios, in order to exclude possible distortions of the scenarios used, having yet been a result pro-productive system of sugar cane a recipe superior to the others of $56.47 \%$ of the gross gain. In scenario 1 , the recipe has been corrected by the Selic rate (BCB, 2019), which provided a result of $43.26 \%$ of surplus, enabled by the cultivation of sugar cane. In scenario 2 , the correction was elaborated in the indexing of revenue in quote production and was converted in the same date of determination of the contract revenue from sugar cane, resulting in $61.45 \%$ of surplus of revenue for the productive system of cane, in which, if the producer had the same production and based on updated quotation, it would also have a lower value. In scenario 3 , the production of the productive system was indexed and corrected by the commercial dollar (BCB, 2019), and the revenue from sugar cane converted into commercial dollar for the calculation, in which the result was even greater for the productive system of sugar cane, reaching a value of $64.69 \%$ higher in relation to their amount. 
Figure 4 presents the production Total Operational Cost (COT) that contemplates the operational disbursements with inputs labor, machinery and administrative expenses, as well as contemplate depreciation and pro-labor (CNA, 2017). In a survey of costs of production of sugar cane suppliers in crop 2016/2017, held in the municipality of Quirinópolis, estimated at $78.31 \%$ of TOC in relation to revenue, according to research by the Confederation of Agriculture and Livestock and CEPEA/Esalq-USP (CNA, 2017). The calculation of revenue is important, but it is also demand that the costs are revealed to check the limits of the reoffering rounds of costs/ha and understand the impact on maximising the profit (Strelecek et al., 2011).

On the other hand, for the purpose of decision-making and produce, the producer needs to parameters that are associated with the impact of spending on your average total cost. It was found that the average total operating cost and the current average operating total cost. In this way, the calculation of the COT held next to the financial controls of agricultural establishments of sugar cane, being that the suppliers stated that with the traditional production systems of the COT was on average $40.77 \%$ in relation to total revenue and with the sugar cane rose to $60.03 \%$ in the $2017 / 2018$ crop. The lessors had a determination of $36.93 \%$, in which fell to $10.19 \%$ the COT with the new productive system.

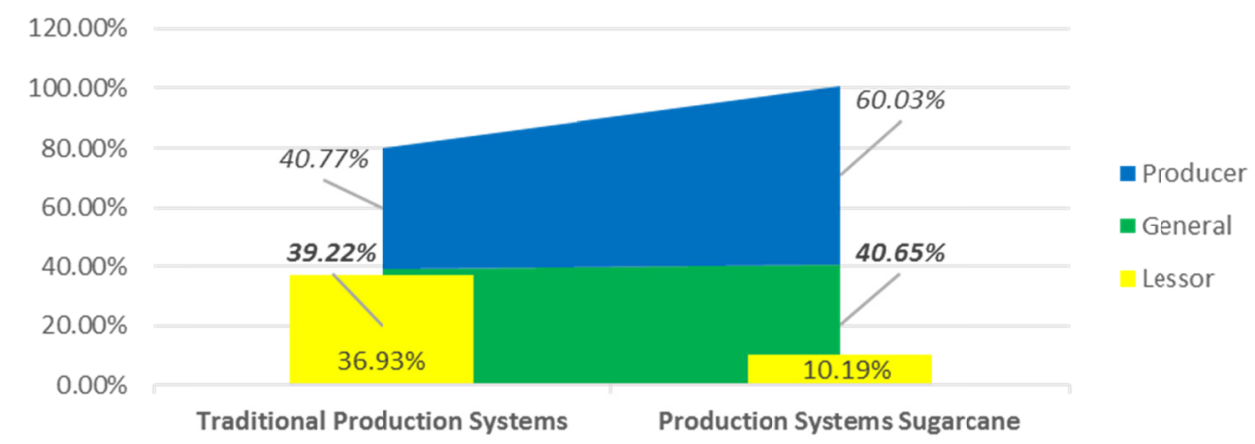

Figure 4. Average total operational cost of the productive systems of agricultural establishments

It is inferred based on the results that the change in the productive system was widely more attractive in terms of cost to the lessors, as for the suppliers, there was an increase of $32.08 \%$ on average, while the lessors occurred a reduction of $262.41 \%$ in relation to previous productive system.

\subsection{Correlation Analysis and Hypothesis Testing}

In this section, we calculated the correlations between the indices of improvement and exodus. For the obtaining of correlations, Spearman's correlation coefficient was used, so that the correlation matrix is presented in Table 6 , in which the values accompanied by “*” are statistically significant at $5 \%$ level of significance, i.e., has $95 \%$ confidence intervals.

Table 6. Matrix of correlations between indexes of rural patrimony and exodus

\begin{tabular}{llllll}
\hline Index & IRPx: extension & IRPx: status & IRPy: size & IRPy: status & IE $_{\text {cana }}$ \\
\hline Division extension & 1 & & & & \\
Division status & $0.333^{*}$ & 1 & & & \\
Size cattle pen & 0.184 & 0.017 & 1 & & \\
Status cattle pen & -0.034 & $0.407^{*}$ & $0.426^{*}$ & 1 & \\
Exodus & -0.139 & $-0.345^{*}$ & -0.110 & -0.207 & 1 \\
\hline
\end{tabular}

According to the results presented in Table 6, we can notice that the indices of extension and condition of the fences are correlated, so that, at the moment that the index of extension increases, the index of state around tends to increase. The indexes of the fence and Corral status are correlated, so that, at the time the index of the fence status increases, the index of corral status also tends to increase. The indexes of the fence status and exodus are correlated, so that, to the extent that the index of the fence status increases, the index of exodus tends to decrease.

The indices of size and condition of corral are correlated, so that, to the extent that the index of the size of the corral increases, the index of corral status tends to increase. The indices of extension and conservation status of 
the rural heritage show a correlation, indicating that, to the extent that reduces or increases, one directly influences on the other. It is important to note that, with greater presence of persons (a lower index of exodus), will also reduce the damage in conservation in fixed improvements of rural properties.

After obtaining the correlations, conducted the tests of hypotheses. For those, before the completion of the tests were conducted the tests of normality of the variables in question, so that the results are presented in Table 7. The normality tests that were used are the following: the Kolmogorov-Smirnov test and Shapiro-Wilk test. With the results presented in Table 7, it is observed that none of the variables under test follows a normal distribution. Therefore, non-parametric tests should be used for the comparison between values. Assuming for the tests of hypotheses, applied the Wilcoxon test for a sample, in order to know if the values of the indices are statistically different from zero. The results are shown in Table 8.

Table 7. Normality tests

\begin{tabular}{lll}
\hline Index & Kolmogorov-Smirnov & Shapiro-Wilk \\
\hline Division extension & $0.000 *$ & $0.000 *$ \\
Division status & $0.000 *$ & $0.000 *$ \\
Size cattle pen & $0.000 *$ & $0.000 *$ \\
Status cattle pen & $0.000 *$ & $0.000 *$ \\
Exodus & $0.000 *$ & $0.000 *$
\end{tabular}

Note. Accompanied Values by “*” means that the respective variable does not follow the normal distribution.

According to the results presented in Table 8, all indices under test are statistically different from zero. Thus, it is concluded that the effects of these indexes are statistically significant at the 5\% significance level $(P<0.05)$, i.e., that have $95 \%$ confidence intervals.

Table 8. Wilcoxon test for the sample

\begin{tabular}{ll}
\hline Index & p-value \\
\hline Division extension & $0.000^{*}$ \\
Division status & $0.000^{*}$ \\
Size cattle pen & $0.000^{*}$ \\
Status cattle pen & $0.000^{*}$ \\
Exodus & $0.000^{*}$ \\
\hline
\end{tabular}

Note. Accompanied Values by “*”.

The conversion of the natural habitat in function of the change of land use has gained great dynamism in the Brazilian territory, about one third of its extension was transformed into an agricultural landscape with areas for productive planting of various crops, food and pastures (Sparovek et al., 2010), in which the sugarcane crop has been largely replacing traditional agricultural and livestock production Gilio and Moraes (2016). The impact of new forms of land use affects the cerrado, caatinga and pampas that have already lost approximately half of the natural vegetation (MMA, 2012), as well as large areas of forest biomes have been deforested (Ribeiro et al., 2009). Figure 5 demonstrates this strong trend in the transformation in land use, where predominantly were pastureland for cattle, with $43.0 \%$, whether for livestock intercropped with the crop, with over $22.4 \%$. In this way, confirmed several current studies that relate the tendency of expansion of sugar cane cultivation preferentially on the areas of pastures, replicating, thus, results of other studies (Roviero, 2014; Egeskog et al., 2016; Spera et al., 2017) conducted in different regions and recent periods.

The Brazilian agricultural diversity combined with the livestock industry form an economic segment with the participation of the vigorous processing industry that has its dynamics involved in this whole process of land use change, where activities such as: chemical transformation; cellulose and printing; production of ethanol, sugar and bioenergy; textile manufacturing; wood and furniture; clothing and footwear industry; production and processing of coffee; vegetable processing in general; slaughter of animals, production of dairy products and derivatives; and other food products are characteristic of the diversity of agriculture in Brazil that gained momentum with the incorporation of the cerrado biome. In this bias, it can be inferred from statistical data that 
the Midwest is the region with the most relevant agroeconomic conditions for sustainable grain production and livestock in Brazil (MMA, 2012).

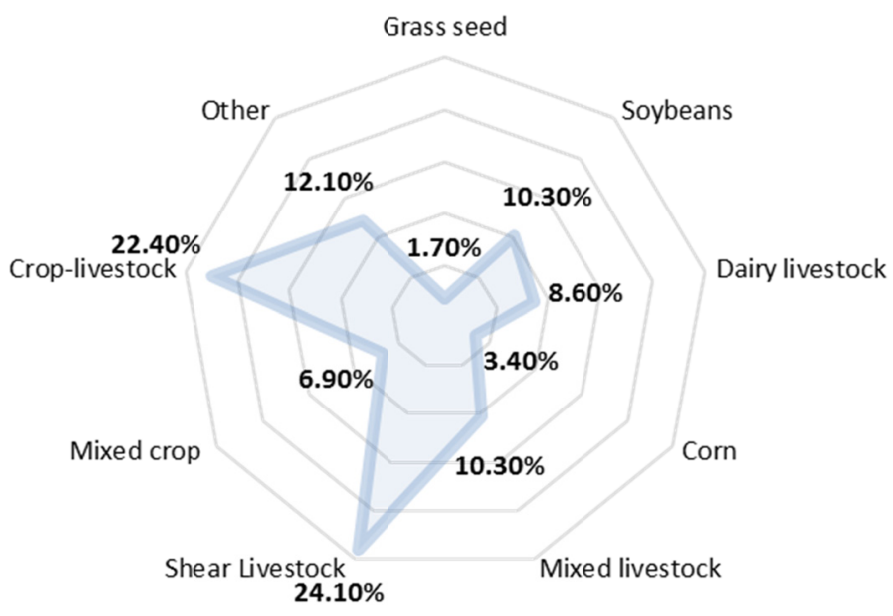

Figure 5. Frequency distribution of land use by developed activity, before the change

Reflecting on Brazil's role as the world's leading producer of food and biofuels, and considering the available studies (Roviero, 2014; Egeskog et al., 2016; Spera et al., 2017; Sparovek et al. 2010; MMA, 2012) one can extract the need for guidelines for the development of agricultural production systems in a more sustainable way, including in relation to sugarcane. The expansion of the sugarcane culture boosted the rapid economic development in different regions, but also replacing other agro-livestock activities, Goiás assumes the role of the main producing pole of the Brazilian center-west, a prominent position and concern due to the great impacts that this change projects on the social, economic and environmental factors. Researchers and public managers should be involved in the formulation of sectoral policies that care for sustainable development, using management solutions that are not restricted to agro-ecological zoning, to effectively guide government and private investments applicable to the agricultural production of sugarcane and at the same time protagonist actions to preserve the Brazilian environment threatened by agro-livestock expansion in general.

\section{Conclusions}

It is concluded that for the municipality of Quirinópolis, the change in land use with the substitution of traditional agro-livestock activities due to sugarcane cultivation aimed at meeting the demands of the sector's agroindustries brought mostly positive socioeconomic impacts, since Quirinópolis evolved its classification in the dimensions health, education, employment and income of the IFDM, obtaining indicators that elevate the municipality to a high development profile. In addition, it was concluded that for sugar cane farms there was a significant improvement in socioeconomic terms with the negative exodus index, strengthening the conception of representativeness among rural producers, improving producer empowerment and increasing profitability and remuneration in all simulated revenue scenarios.

\section{Acknowledgements}

The authors thank the Federal Institute of Goiano (IFGoiano), Rio Verde.

\section{References}

Assunção, J., Pietracci, B., \& Souza, P. (2016). Fueling development: Sugarcane expansion impacts in Brazil. Climate Policy Initiative.

Barnes, A. P., Hansson, H., Manevska-Tasevska, G., Shrestha, S. S., \& Thomson, S. G. (2015). The Influence of Diversification on long-term Viability of the Agricultural Sector. Land Use Policy, 49, 404-412. https://doi.org/10.1016/j.landusepol.2015.08.023

BCB, Banco Central do Brasil. (2019). Access to Central Bank information: Application Citizen's calculator. Retrieved from https://www3.bcb.gov.br/CALCIDADAO/publico/exibirFormCorrecaoValores.do?method= exibirFormCorrecaoValores\&aba $=4$

CEPEA (Centro de Estudos Avançados em Economia Aplicada). (2018A). Brazilian Agribusiness GDP. Retrieved from https://www.cepea.esalq.usp.br/br/pib-do-agronegocio-brasileiro.aspx 
CEPEA (Centro de Estudos Avançados em Economia Aplicada). (2018B). Database query. Retrieved from https://www.cepea.esalq.usp.br/br/consultas-ao-banco-de-dados-do-site.aspx

CNA (Confederação da Agricultura e Pecuária do Brasil). (2017). The survey of production costs of sugarcane from suppliers in the 2016/2017 harvest. Sugarcane Assets Report. CNA and Cepea/Esalq-USP.

CONSECANA (Conselho de Produtores de Cana-de-Açúcar, Açúcar e Etanol do Estado de São Paulo). (2018). Database. Retrieved from https://www.consecana.com.br/login.asp?url=preco_mensal.asp

Cooper, D. R., \& Schindler, P. S. (2016). Research Methods in Administration (12th ed.). Porto Alegre: Bookman.

Creswell, J. W. (2017). Research Design: Qualitative, Quantitative, and Mixed Methods Approaches. SAGE Publications.

Dauvergne P., \& Neville, K. J. (2010). Forests, food, and fuel in the tropics: The uneven social and ecological consequences of the emerging political economy of biofuels. J. Peasant Stud., 37(4), 631-660. https://doi.org/10.1080/03066150.2010.512451

Duarte, C. G., Gaudreau, K. Gibson, R. B., \& Malheiros, T. F. (2013). Sustainability assessment of sugarcane-ethanol production in Brazil: A case study of a sugarcane mill in São Paulo state. Ecological Indicators, 30, 119-129. https://doi.org/10.1016/j.ecolind.2013.02.011

Dzanja, J. (2018). Characterization of Social Capital Using a Nested Latent Class Model: Case of Rural Areas in Central Malawi. Journal of Agricultural Science, 10(4). https://doi.org/10.5539/jas.v10n4p178

Egeskog, A., Barretto, A., Berndes, G., Sparovek, G., Freitas F., Holmén, M., \& Torén, J. (2016). Actions and opinions of Brazilian farmers who shift to sugarcane-An interview-based assessment with discussion of implications for land-use change. Land Use Policy, 57, 594-604. https://doi.org/10.1016/j.landusepol. 2016.06.022

FIRJAN, Federação das Indústrias do Estado do Rio de Janeiro. (2018). Índice FIRJAN de Desenvolvimento Municipal (IFDM). Retrieved from https://www.firjan.com.br/ifdm/consulta-ao-indice

Garrett, R. D., Lambin, E. F., \& Naylor, R. L. (2013). The new economic geography of land use change: Supply chain configurations and land use in the Brazilian Amazon. Land Use Policy, 34, $265-275$. https://doi.org/10.1016/j.landusepol.2013.03.011

Gilio, L., \& Moraes, M. A. F. D. (2016). Sugarcane industry’s socioeconomic impact in São Paulo, Brazil: A spatial dynamic panel approach. Energy Econ., 58, 27-37. https://doi.org/10.1016/j.eneco.2016.06.005

Guanziroli, C., Buainain, A., \& Sabbato, A. (2013). Family farming in Brazil: Evolution between the 1996 and 2006 agricultural censuses. J. Peasant Stud, 40(50), 817-843. https://doi.org/10.1080/03066150.2013. 857179

IBGE (Instituto Brasileiro de Geografia e Estatística). (2018a). Agricultural Census-Preliminary results, 2017. Retrieved from https://sidra.ibge.gov.br

IBGE (Instituto Brasileiro de Geografia e Estatística). (2018b). Cities. Retrieved from http://cidades.ibge.gov.br/ xtras/home.php

IPEA, (Instituto de Pesquisa Estatística Aplicada). (2016). Data referring year 2016. Retrieved from http://www.ipea.gov.br/portal

IPEA (Instituto de Pesquisa Estatística Aplicada). (2018). Database. Retrieved from https://www.cepea.esalq. usp.br/br/consultas-ao-banco-de-dados-do-site.aspx

Maia, C., Fideles, J., \& Medina, G. (2016). Agrarian Reform. In G. Medina (Ed.), Family agriculture in Goiás: Lessons for Technical Assistance. Goiânia: Publisher of UFG.

Mangoyana, R. B., Smith, T. F., \& Simpson, R. A. (2013). Systems approach to evaluating sustainability of biofuel systems. Renew. Sustain. Energy Rev., 25, 371-380. https://doi.org/10.1016/j.rser.2013.05.003

Maroun, M. R., \& Rovere, E. L. (2014). Ethanol and food production by family smallholdings in rural Brazil: economic and socio-environmental analysis of micro distilleries in the State of Rio Grande do Sul. Biomass \& Bioenergy, 63, 140-155. https://doi.org/10.1016/j.biombioe.2014.02.023

Medina, G., Almeida, C., Novaes, E., Godar, J., \& Pokorny, B. (2015). Development conditions for family farming: lessons from Brazil. World Development, 74, 386-396. https://doi.org/10.1016/j.worlddev. 2015.05 .023 
MMA (Ministério do Meio Ambiente). (2012). The technical report on deforestation in the closed biome, from 2002 to 2008

Myers, J. L., Well, A. D., \& Jr., R. F. L. (2013). Research Design and Statistical Analysis (3rd ed.). Routledge, New York.

Oliveira, B. G., Liboni, L. B., \& Calia, R. C. (2014a). Do sugarcane producing regions have better social-economic development? A study using “ Índice Firjan de Desenvolvimento Municipal (IFDM). GCG Georgetown University-Universia.

Oliveira, T. B., Bornia, A. C., Silveira, S. d., Drumond, A. M., \& Oliveira, M. W. (2014b). Análise de Custos e Eficiência de Fazendas Produtoras de Cana-de-Açúcar por Meio da Análise Envoltória de Dados. Custos e @gronegócios On-line, 10(1), 228-252.

Pereira, G. A., \& Moreira, T. B. S. (2016). The Influence of health intermunicipal consortium in the Índice FIRJAN de Desenvolvimento Municipal (IFDM). Revista Planejamento e Políticas Públicas.

Petrini, M. A., Rocha, J. V., \& Brown, J. C. (2017). Mismatches between mill-cultivated sugarcane and smallholding farming in Brazil: Environmental and socioeconomic impacts. Journal of Rural Studies, 50, 218-227. https://doi.org/10.1016/j.jrurstud.2017.01.009

Petrini, M. A., Rocha, J. V., Brown, J. C., Bispo, R. C. (2016). Using an analytic hierarchy process approach to prioritize public policies addressing family farming in Brazil. Land Use Policy, 51, 85-94. https://doi.org/ 10.1016/j.landusepol.2015.10.029

Ribeiro, B. E. (2013). Beyond commonplace biofuels: Social aspects of ethanol. Energy Policy, 57, $355-362$. https://doi.org/10.1016/j.enpol.2013.02.004

Ribeiro, M. C., Metzger, J. P., Martensen, C. A., Ponzoni, F. J., \& Hirota, M. M. (2009). The Brazilian Atlantic Forest: How much remains and how the remaining forest is distributed? Implications for conservation. Biological Conservation, 142, 1141-1153. https://doi.org/10.1016/j.biocon.2009.02.021

Roviero, A. (2014). Study of small producers and suppliers of sugarcane and land for the sugar and alcohol mills in the interior of São Paulo: The case of the central region of the State of São Paulo. REDD-Revista Espaço de Diálogo e Desconexão, 8(1\&2).

Santos, G. E. O. (2016). Sample calculation: Online calculator. Retrieved from http://www.calculoamostral. vai.la

Santos, M. R. da S., Vitorino, M. I., \& Pimentel, M. A. S. (2017). Vulnerabilidade e mudanças climáticas: análise socioambiental em uma mesorregião da Amazônia. Revista Ambiente \& Água, 12(5), 842-854. https://doi.org/10.4136/ambi-agua.2017

Simms, A., Freshwater, D., \& Ward, J. (2014). The Rural Economic Capacity Index (RECI): A Benchmarking Tool to Support Community-Based Economic Development. Economic Development Quarterly, 28(4), 351-363. https://doi.org/10.1177/0891242413512672

Sparovek, G., Berndes, G., Klug, I. L. F., \& Barretto, A. G. O. P. (2010). Brazilian agricultural and environmental legislation: status and future challenges. J. of Environmental Science and Technology, 44, 6046-6053. https://doi.org/10.1021/es1007824

Spera, S., VanWey, L., \& Mustard, J. (2017). The drivers of sugarcane expansion in Goiás, Brazil. Land Use Policy, 66, 111-119. https://doi.org/10.1016/j.landusepol.2017.03.037

Strelecek, F., Zdenek, R., \& Lososová, J. (2011). Influence of the production change on the return to scale. Agricultural Economics, 57(4), 159-168. https://doi.org/10.17221/93/2010-AGRICECON

Trindade, S. P. (2015). Agricultural aptitude, changes in land use, conflicts and direct and indirect impacts of sugarcane expansion in the southwestern region of Goiás (187f, Tese Doctorate degree in Environmental Sciences, Universidade Federal de Goiás, Goiânia).

\section{Copyrights}

Copyright for this article is retained by the author(s), with first publication rights granted to the journal.

This is an open-access article distributed under the terms and conditions of the Creative Commons Attribution license (http://creativecommons.org/licenses/by/4.0/). 